\title{
JOHN HUGHLINGS JACKSON, r835-rgrr.
}

\author{
By WILFRED HARRIS, M.D. \\ (Consulting Physician, St. Mary's Hospital.)
}

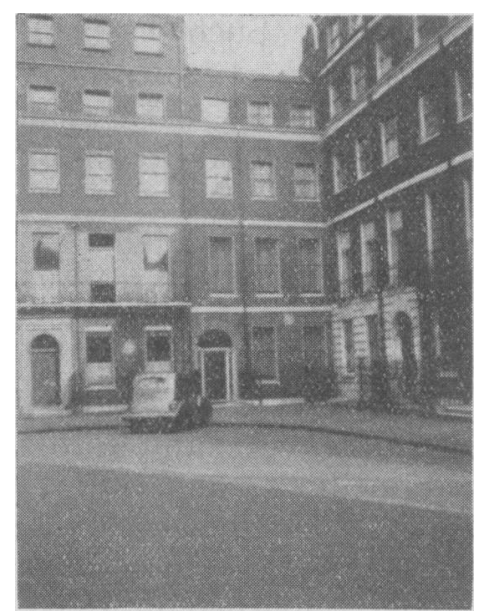

Nos. 2, 3 \& 4 Manchester Square, W.1. Dr. Hughlings Jackson occupied No. (house in corner facing) from 1871 till his death in 1911 .

John Hughlings Jackson was born on 4th April I835, of yeoman parentage, near York, and after education at two or three small schools, was apprenticed to a doctor in York on the staff of the local medical school.

In the early fifties, two years' study was sufficient for qualification, and after a short period at St. Bartholomew's Hospital, he qualified M.R.C.S. and L.S.A. in London in I856, and then returned as house surgeon to the York Dispensary, a post he held for over two years, as late in 1858 he wrote to the Registrar of the General Medical Council asking to be registered under the new Medical Act, his registration being dated Ist January I859, the earliest possible date. Though this was the first day of registration for medical practitioners, the number of his registration was 3878 .

While still a student apprentice at York, he probably was first attracted to neurology by the teachings of Thomas Laycock, physician to the City Dispensary, whose writings on the Reflex Functions of the Brain and his later treatise "Mind and Brain," published in I860, no doubt powerfully influenced Jackson in his bent towards neurological science. Laycock had gone to Edinburgh in I855 as Professor of the Practice of Physic before Jackson returned to York on qualification, but he soon fell under the influence of Brown-Séquard on his return to London in I859. He lived first for two years at I4, Finsbury Circus, moving to No. 4 in I86I. Both these houses have now disappeared, and have been replaced by a large block of offices.

At first he worked with Jonathan Hutchinson in collecting material from various hospitals for the medical journals, and it was his early mentor, Hutchinson, who first taught him the value of ophthalmoscopy and the importance of the eye generally in neurology.

Jackson would sometimes take a case from his wards at the National to Hutchinson's Wednesday demonstrations at I, Park Crescent, the forerunner of the Polyclinic in Chenies Street, now, alas, defunct. The writer, when his house physician, well remembers Jackson taking a somewhat obscure case of pupil change and diplopia, on such an occasion, and Hutchinson, a taller man, demonstrating the case, with raised forefinger, to Jackson, as though he were still a student at his feet.

To Hutchinson also we owe the fact that he dissuaded Jackson from giving up medicine for philosophy. Jackson had a great admiration for Herbert Spencer and his philosophical writings, which greatly influenced his modes of thought and 
deduction in his later neurological essays. Herbert Spencer first used the term dissolution as opposed to evolution, and in an article on "Dissolution of the Nervous System," published in the Medical Press and Circular in I88I, page 329, Jackson writes:- "Readers will not of course judge Spencer's doctrines from my application of them. I should take it as a great calamity were any crudities of mine to be attributed to this distinguished thinker." Such was his modesty, and his meticulous care in giving credit to others.

Though his publications on epileptiform convulsions and cerebral localisation soon led to this form of epilepsy being known as Jacksonian epilepsy, he never ceased to point out that the French physician, Bravais, had drawn attention to the type forty years previously. Jackson was the first to describe the "dreamy state" and olfactory aura associated with epileptic attacks in tumours of the temporal lobe, named by him "uncinate epilepsy."

Sir Farquhar Buzzard in his Schorstein lecture ${ }^{(1)}$ last year gave examples of his accuracy in note taking, of his avoidance of slipshod methods, and of his brilliancy of deduction and generalisation after a study of all the known facts. Jackson worked much with Crichton Browne, and published no less than five articles in the West Riding Asylum Reports, in which Ferrier published in I873 the results of his experiments on cerebral localisation, which confirmed many of Hughlings Jackson's previous speculations. At first Jackson believed the occipital convolutions were the highest sensory centres, being misled by Ferrier's announcement of the angular gyrus being the visual centre. His views on "Evolution and Dissolution of the Nervous System" were finally co-ordinated in his Croonian Lectures in I884, dividing the central nervous system into three levels:-

(I) The præfrontal, or the highest sensori-motor centre, as " organ of mind, the physiological basis of consciousness."

(2) The middle level, the so-called " motor area," with the corpus striatum.

(3) The lowest level, or spino-medullary.

Jackson pointed out that dissolution began in the highest centres, and that symptoms found in their disease were not produced by the lesion, but were due to the then unrestrained activity of lower centres. As he said, "Destructive lesions never cause positive effects, but induce a negative condition which permits positive symptoms to appear." Thus he compared the activity of the cerebrum and cerebellum as being largely opposed in their motor effects upon the skeletal muscles, theories later proved by Sherrington experimentally in the decerebrate animal.

In his views on aphasia, Jackson was opposed to the school of diagram makers, led by Bastian in this country, and by Lichtheim and others on the Continent. These appealed by their apparent mechanical simplicity, and Jackson's psychological aspect of the question and his somewhat involved and 
difficult papers were largely overlooked until Henry Head in "Brain" in I9I5, and later in his work on "Aphasia" in I926, showed how Jackson's theories had stood the test of time and experience.

Brown-Séquard's famous series of twelve lectures on the "Physiology and Pathology of the Central Nervous System," published in the "Lancet" in I858, must have attracted Jackson's attention while still in York, and shortly after when in I860 Brown-Séquard became physician to the recently founded National Hospital in Queen Square, his influence upon Jackson persuaded him to devote himself to neurology, against Hutchinson's advice. Already on the staff of the London Hospital as a colleague of Hutchinson, he became Assistant Physician to the National Hospital in I862 and went to live at No. 5 Queen Square, pow pulled down, near the Hospital. At first he did not like the work of visiting the outpatients in their homes, and actually sent in his resignation, but withdrew it on his objections being met.

In I867 he was appointed full Physician to the National Hospital, which post he held for nearly forty years until he retired as Consulting Physician in 1906. In this interval his industry was prodigious, but he never published a book, all his writings being in various articles, often in obscure journals. ${ }^{(2)}$ When pressed as to his reasons for not writing a text book, he would say that if he were to do that his enemies would find him out. Probably he had fewer enemies than any other successful man who rose to such a height of recognised pre-eminence, but his mentality was not of the type that could sit down to work regularly week after week, and month after month, at the routine of text-book writing. In a sense he might be called lazy. He would soon get bored and give up an argument and go away by himself; he hated exercise and would rather sit over a novel by the fire than go for a walk in the winter sunshine.

Sir Farquhar Buzzard, who knew him well, as his father was a close personal friend and colleague of Jackson, gives an interesting sketch of Jackson's friendly relations with the family. Generally kindness itself, yet in some respects he was a hard taskmaster and thoughtless of others. He might invite a house physician to drive with him down to the Poplar Hospital to see a patient in whom they were both interested, and on the return journey he would perhaps get bored with his young companion, and stop the carriage in the Commercial Road and say to him, "You will find your way quite easily from here!"

In the sixteen years from I893-I909 he published a large number of "Neurological Fragments" in the "Lancet," since collected in volume form ${ }^{(3)}$ by James Taylor, and he was a great trial on many occasions to the Editorial Staff in insisting on repeated proofs, and requiring immediate publication, often when impossible.

He was a solitary soul for the last 35 years of his life after his wife's death. Married in I865 to his cousin, they went to live at 28 , Bedford Place, moving in I87I to 3, Manchester Square, where he lived until his death. Both these houses remain, and the latter is now marked by a plaque put up by the L.C.C. to commemorate the fact that "John Hughlings Jackson, I87I-I9II, Physician, 
lived here." Somewhat melancholic in tinge, his personality was yet one which appealed immensely to those who worked under him, as he would often illuminate what appeared to be a dull, ordinary case by pointing out unnoticed signs and symptoms. Such might illustrate some of his theories, and stimulate his hearer in research, and especially in the accurate observation and recording of history, symptoms and signs, with absolute truthfulness and disregard of bias.

Jackson had no respect for books as such, and he would buy a book at a stall, pull off the covers, and then tear the volume in halves, and cram each half into a side pocket. "You may think me mad to do so," he would say, but he felt that books were made for convenient use, and not for ornament and preservation.

He had a pawky humour, and would relate a story with a perfectly grave face, with only a tell-tale twinkle in his eye. He wrote in his early years an article on the Psychology of Joking, dividing humour into three levels, like his evolutionary levels of the cerebrum, viz., punning, witticisms, and humorous stories. Punning was his lowest form of wit, a " mental diplopia."

Of middle height, he wore a bushy beard and moustache of the Victorian fashion, a buttoned-up frock coat. black stiff made-up tie and open collar. $\mathrm{He}$ was deaf in the left ear and for many years in the latter half of his life was subject to attacks of labyrinthine vertigo. Myopic in one eye and emmetropic in the other, a most useful combination, as he said, he never required glasses, reading with the one and using the other for distant vision. $\mathrm{He}$ always drove about in a landau and pair, a well-known figure as he sat in the left-hand corner seat with his top hat hiding his features. A quaint conceit of his was his method of initialling this hat with four oblique strokes $/ / / /$ on the lining, for J.H.J.

He was one of the four first editors of "Brain," of whom Sir James Crichton Browne alone remains to us. "Brain" appeared first in I878 in quarterly numbers, and the last quarter of 1906 was devoted to Jackson, with his portrait, in commemoration of his fifty years' medical practice. In I886 the Neurological Society of London was founded, and he became its first President, giving his inaugural address "On the Scope and Aims of Neurology." In I897 the Neurological Society founded the "Hughlings Jackson Lecture," to be given triennially, and the first lecture was given by Jackson himself on 8th December, I897, at the Medical Society's Rooms in Chandos Street. (See "Lancet," I898, $I, 79$.) This lecture, given intermittently, was interrupted by the war, and none was given between I909 and I920, but since Sir Charles Sherrington's lecture No in I93I the lectureship has been endowed with a gold medal and honorarium of $N$ Ioo guineas by a world-wide subscription in I932. Thus, over 20 years since $\underset{\omega}{~}$ Jackson's death in I9II, his name and teaching remain as a revered memory 0 and example to the diminishing few who knew him, and as a tradition to past, present and future generations of students in the art of observation and deduction.

REFEREATCES.

(1) Lancet, 1934, 11, 909.

(2) vide Selected Writings of John Hughlings Jackson. 2 Vols. by James Taylor (Hodder \& Stoughton).

(3) Oxford Medical Publications, 1925. 